\title{
AVALIAÇÃO DAS PERDAS DE NITRATO EM SOLO IRRIGADO À DIFERENTES QUANTIDADES DE RADIAÇÃO SOLAR ${ }^{1}$
}

\author{
Mônica Sarolli Silva ${ }^{2}$, Luiz Antonio de Mendonça Costa ${ }^{3}$, Mario Benincasa ${ }^{4}$ e Jorge de Lucas $\mathrm{Jr}^{5}$
}

\begin{abstract}
RESUMO
Estudou-se o efeito da irrigação e da incidência diferenciada da radiação solar em uma bacia hidrográfica experimental, sobre um Latossolo Roxo distrófico, enriquecido com efluente de biodigestor anaeróbio, fonte de matéria orgânica, com o objetivo de acompanhar as perdas de nitrato causadas tanto pela lixiviação como pela diferentes microclimas no solo. Analisando-se os resultados obtidos, observou-se que a irrigação efetuada no período de 21 dias provocou uma grande perda de nitrato em todas as rampas estudadas. Com relação ao efeito da quantidade diferenciada de radiação solar incidente sobre a superfície do substrato (solo + efluente) observou-se que esta causou variações nos valores de temperatura e umidade do solo, a ponto de definir diferentes ambientes e provocar perdas de nitrato mais acentuadas nas rampas com exposição norte.
\end{abstract}

Palavras-chave: radiação solar, efluente de biodigestor, temperatura, umidade

\section{EVALUATION OF LOSS OF NITRATE IN IRRIGATED SOIL SUBMITTED TO DIFFERENT QUANTITES OF SOLAR RADIATION}

\begin{abstract}
The effect of the irrigation and solar radiation incidence in a soil previously enrichad with anaerobic biodigestor effluent, source of organic matter, at experimental hydrographic basin was studied with the aim to evaluate the losses of nitrate content caused by the leaching and by different microclimates in the soil. dimicrosites. Analyzing the results it was observed that the irrigation during 21 days caused an appreciable loss of nitrate content in all slopes. With regard to effect of differential quantity of solar radiation and substrate (soil + effluent) it caused variations in temperature and moisture content to the extent to form different environments causing more intensive nitrate loss in the slopes with north exposition.
\end{abstract}

Key-words: solar radiation, biodigestor effluent, temperature, moisture, organic matter

\section{INTRODUÇÃO}

Durante seu ciclo, o nitrogênio do protoplasma celular é decomposto, passando da forma orgânica para a inorgânica, pela ação de uma série de bactérias decompositoras, cada uma delas especializada em realizar parte do processo. Parte desse nitrogênio se transforma em amônia e nitrato, que são formas mais facilmente utilizadas pelas plantas verdes, através dos processos de amonificação e, posteriormente, de nitrificação (Odum, 1988). O nitrato é um ânion não retido pelo complexo argilo-úmido do solo que, sob a ação das águas de infiltração, é

${ }^{1}$ Pesquisa financiada pela FAPESP

${ }^{2}$ M. Sc. Prof. Assistente da UNIOESTE - CP 91 CEP 85960-000 Marechal Cândido Rondon, PR

${ }^{3}$ Eng. Agrônomo M. Sc. Produção Vegetal. Av. Írio J. Welp 1149 (F) CP 85960-000 Fone (045) 254-2025 Marechal Cândido Rondon PR

${ }^{4}$ Pesquisador Prof. Titular do CEA/UNESP - Rio Claro, SP

${ }^{5}$ Prof. Adjunto da FCA/UNESP - Jaboticabal, SP 
arrastado em profundidade para fora do alcance das raízes das plantas; diz-se, então, que ele foi lixiviado. Essa lixiviação tem lugar essencialmente no período invernal, quando o balanço hídrico (chuva-evaporação) se torna excedente e a água não retida pelo solo percola por gravidade e realimenta, em seguida, os aquíferos (Agioda et al., 1994). Outra forma pela qual o nitrato é perdido, ocorre pelo processo de desnitrificação, que corresponde à redução do nitrito ou do nitrato a nitrogênio gasoso e é o processo pelo qual o $\mathrm{N}_{2}$ fixado do ar, por via industrial ou biológica, é devolvido à atmosfera. Condições anaeróbias, com restrição de $\mathrm{O}_{2}$ ou com grandes quantidades de compostos orgânicos reduzidos, favorecem a desnitrificação, pois os microrganismos desnitrificadores usam os óxidos $\mathrm{NO}_{3}^{-}, \mathrm{NO}_{2}^{-}, \mathrm{NO}$ ou $\mathrm{N}_{2} \mathrm{O}$ como receptores terminais de elétrons (Siqueira \& Franco, 1988); entretanto, além das implicações agronômicas deste processo as perdas de nitrato do solo apresentam conseqüências graves ao meio ambiente e à saúde humana.

$\mathrm{O}$ nitrogênio da molécula de óxido nitroso $\left(\mathrm{N}_{2} \mathrm{O}\right)$ é um elemento que, à semelhança do carbono, exerce ação no aquecimento global e provém, basicamente, da transformação de fertilizantes nitrogenados no solo, de dejetos animais, de água subterrânea contaminada com nitrato e, também, da queima da fitomassa. É importante observar que o nitrito, quando presente na água, combina-se com compostos aminados e transforma-se em nitrosaminas, que são carcinogênicas (Siqueira et al., 1994). Além disso, o nitrato é reduzido a nitrito no organismo humano ou animal e este, ao se formar, causa a oxidação do $\mathrm{Fe}^{+2}$ a Fe $\mathrm{Fe}^{+3}$ da fração heme da hemoglobina, convertendo-a em metamoglobina reduzindo, assim, a capacidade do sangue de transportar oxigênio dos pulmões para o resto do corpo (Siqueira \& Franco, 1988).

Esta instabilidade do nitrogênio no solo, segundo Kiehl (1985) está aliada às condições de drenagem, topografia, textura do solo, práticas culturais e estações do ano; solos mais úmidos, mais planos, de textura fina, recebendo bom manejo, nas épocas mais frias do ano têm condições para, de maneira geral, acumular mais nitrogênio proveniente da decomposição da matéria orgânica.

Desta forma, pode-se dizer que a radiação solar incidente sobre a superfície do solo é fator determinante e condiciona os processos que ocorrem nesse ambiente, interferindo sobremaneira no ciclo dos nutrientes. Sendo assim e variando a quantidade de radiação solar incidente, pode-se obter condições ambientais diferenciadas e, por conseguinte, promover alteração nos demais processos.

Os efeitos diretos que a incidência diferenciada da radiação solar causam na superfície do solo, podem ser constatados através da determinação da temperatura e umidade deste; contudo, contrariamente ao estudo em laboratório, em condições de campo inúmeras são as variáveis que influenciam os resultados obtidos. A análise desses resultados deve ser feita, então, de forma ampla, levando-se em consideração, sempre que possível, o maior número de variáveis do meio e suas interações.

Objetivou-se, no presente estudo, acompanhar e avaliar as perdas de nitrato em um solo que recebeu efluente de biodigestor anaeróbio como fonte de matéria orgânica e nutrientes, quando submetido à ação de irrigação e de diferentes quantidades de radiação solar incidente.

\section{MATERIAL E MÉTODOS}

A pesquisa foi instalada em área experimental do Departamento de Engenharia Rural da UNESP, Campus de Jaboticabal, SP, em uma bacia hidrográfica experimental, tal estrutura consta de doze rampas de terreno com declividades de 0 (Horizontal), 10, 20, 30, 40 e 50\% nas exposições norte e sul.

$\mathrm{O}$ substrato com o qual foram preenchidas as rampas foi composto de uma mistura de $18 \mathrm{~m}^{3}$ de solo (Latossolo Roxo distrófico) e 14 mil L de biofertilizante, cuja composição química média é apresentada na Tabela 1. A mistura do substrato foi realizada de uma só vez, manualmente e, após a secagem, procedeu-se à operação de destorroamento através de enxada rotativa, seguida de peneiramento, para que a homogeneização fosse mais eficiente. Cada rampa recebeu quantidade suficiente de substrato para preencher a camada de $0-10 \mathrm{~cm}$ e, uma vez preenchidas, iniciou-se a coleta de dados.

Tabela 1. Composição química média do biofertilizante

\begin{tabular}{cccccccccc}
\hline $\mathrm{N}$ & $\mathrm{C}$ & $\mathrm{P}$ & $\mathrm{K}$ & $\mathrm{Ca}$ & $\mathrm{Mg}$ & $\mathrm{Cu}$ & $\mathrm{Zn}$ & $\begin{array}{c}\mathrm{Fe} \\
\%\end{array}$ & $\begin{array}{c}\mathrm{Mn} \\
\%\end{array}$ \\
$\%$ & $\%$ & $\%$ & $\%$ & $\mathrm{~g} \mathrm{dm}^{-3}$ & $\mathrm{~g} \mathrm{dm}^{-3}$ & $\mathrm{~g} \mathrm{dm}^{-3}$ & $\mathrm{~g} \mathrm{dm}^{-3}$ \\
\hline 1,09 & 44,5 & 0,73 & 3,10 & 0,89 & 0,62 & 83 & 13,15 & 35.675 & 5,80 \\
\hline
\end{tabular}

A irrigação das rampas deu-se diariamente, no período de 13/08 a 02/09, perfazendo o total de 21 dias, através de rega com cano perfurado, durante $10 \mathrm{~min}$. em cada rampa, a uma vazão média de $0,36 \mathrm{~L} \mathrm{~s}^{-1}$, totalizando aproximadamente $217 \mathrm{~L} \mathrm{dia}^{-1}$. Diariamente e de forma contínua foram coletados os dados de radiação solar global incidente sobre a horizontal $(0 \%)$ por meio de piranômetro. Para as demais rampas, os dados de radiação solar foram estimados a partir de modelo desenvolvido por Latanze et al. (1987) enquanto a temperatura do solo foi medida a 2,0 e a 5,0 cm de profundidade, com observações diárias em vários horários, com auxílio de geotermômetros de mercúrio em vidro, com precisão de $0,2^{\circ} \mathrm{C}$. A umidade do solo foi estimada na camada de $0-5,0 \mathrm{~cm}$, semanalmente, através do método gravimétrico (Kiehl, 1985). O teor de nitrato do solo foi determinado através do método do ácido fenoldissulfônico, adaptado por Roller \& Mc Kaig (1939) e Black (1957) apud Evans et al. (1965).

\section{RESULTADOS E DISCUSSÃO}

\section{Radiação solar global}

Os valores de radiação solar global, apresentados no Tabela 2, evidenciam a diferença quanto à incidência dos raios solares, provocada pela variação da declividade e exposição do terreno e, também, pela época do ano; assim, pode-se observar que as rampas com exposição sul receberam menor quantidade de radiação solar que as rampas com exposição norte, principalmente no início do experimento, de julho a setembro, e maior quantidade de radiação solar no período de setembro a dezembro (Figura 1).

Além das maiores diferenças de radiação solar entre as exposições, observam-se também diferenças entre as declividades. Nas rampas com face norte, os valores de radiação solar cresceram com a declividade, isto é, quanto maior a inclinação da rampa, maior também a quantidade de radiação solar recebida; já nas rampas com face sul observa-se o oposto: quanto maior a inclinação, menor a incidência dos raios solares. 
Tabela 2. Radiação solar global* em rampas com 0, 10, 20, 30, 40 e 50\% de declividade e exposições norte e sul

\begin{tabular}{|c|c|c|c|c|c|c|c|c|c|c|c|}
\hline \multirow[t]{2}{*}{ Período } & \multicolumn{11}{|c|}{ Radiação Solar Global (cal cm ${ }^{-2}$ dia $\left.^{-3}\right)$} \\
\hline & $\mathrm{H}$ & $10 \mathrm{~N}$ & $10 \mathrm{~S}$ & $20 \mathrm{~N}$ & $20 \mathrm{~S}$ & $30 \mathrm{~N}$ & $30 \mathrm{~S}$ & $40 \mathrm{~N}$ & $40 \mathrm{~S}$ & $50 \mathrm{~N}$ & $50 \mathrm{~S}$ \\
\hline $15-21 / 06$ & 295,7 & 332,1 & 257,3 & 364,5 & 218,2 & 392,4 & 179,2 & 415,7 & 142,0 & 434,4 & 107,4 \\
\hline $22-28 / 06$ & 353,8 & 396,4 & 308,4 & 434,4 & 261,9 & 467,0 & 251,6 & 494,1 & 171,2 & 515,9 & 129,6 \\
\hline $29 / 06-05 / 07$ & 315,5 & 376,0 & 276,4 & 383,8 & 236,1 & 411,3 & 195,8 & 434,0 & 156,7 & 452,0 & 120,1 \\
\hline $06-12 / 07$ & 327,5 & 364,6 & 287,2 & 397,4 & 245,8 & 421,9 & 204,3 & 448,5 & 164,1 & 466,9 & 126,3 \\
\hline $13-19 / 07$ & 261,2 & 291,6 & 230,5 & 318,5 & 198,6 & 341,6 & 165,5 & 360,7 & 135,2 & 375,9 & 105,8 \\
\hline $20-26 / 07$ & 378,7 & 419,6 & 335,9 & 455,6 & 291,5 & 486,1 & 240,9 & 511,1 & 202,8 & 530,7 & 161,4 \\
\hline $27 / 07-02 / 08$ & 283,6 & 310,7 & 254,0 & 334,4 & 222,8 & 354,1 & 191,2 & 369,9 & 160,1 & 382,0 & 130,3 \\
\hline $03-09 / 08$ & 407,8 & 444,7 & 367,0 & 476,6 & 324,3 & 530,0 & 280,6 & 524,0 & 237,5 & 539,7 & 196,2 \\
\hline $10-16 / 08$ & 320,2 & 345,7 & 291,5 & 367,4 & 260,9 & 384,9 & 229,1 & 398,4 & 197,3 & 408,1 & 166,4 \\
\hline $17-23 / 08$ & 253,7 & 272,3 & 232,6 & 287,9 & 209,6 & 300,3 & 186,0 & 309,7 & 162,2 & 316,2 & 139,0 \\
\hline $24-30 / 08$ & 410,3 & 437,0 & 379,6 & 458,9 & 345,8 & 475,8 & 310,3 & 488,1 & 274,4 & 496,0 & 238,9 \\
\hline $31 / 08-06 / 09$ & 384,6 & 412,3 & 358,4 & 435,4 & 330,1 & 453,8 & 299,9 & 467,5 & 268,9 & 476,9 & 238,3 \\
\hline $07-13 / 09$ & 304,4 & 319,4 & 286,4 & 331,0 & 266,4 & 339,2 & 244,9 & 344,2 & 225,5 & 346,4 & 200,1 \\
\hline $14-20 / 09$ & 373,4 & 388,5 & 354,5 & 399,6 & 332,6 & 406,7 & 308,5 & 410,1 & 283,3 & 410,4 & 257,8 \\
\hline $21-27 / 09$ & 263,9 & 272,4 & 252,7 & 278,2 & 239,3 & 281,3 & 224,2 & 281,9 & 208,1 & 280,4 & 191,6 \\
\hline 28/09-04/10 & 494,9 & 507,2 & 477,6 & 514,5 & 459,3 & 516,9 & 431,2 & 514,9 & 404,1 & 509,4 & 376,0 \\
\hline $05-11 / 10$ & 538,6 & 548,4 & 523,5 & 552,8 & 503,6 & 551,9 & 479,9 & 546,7 & 453,5 & 537,9 & 425,7 \\
\hline $12-18 / 10$ & 426,9 & 432,2 & 417,4 & 433,2 & 404,4 & 430,3 & 387,5 & 424,0 & 368,7 & 415,2 & 348,5 \\
\hline $19-25 / 10$ & 493,9 & 496,3 & 488,7 & 494,2 & 478,9 & 487,8 & 465,1 & 477,7 & 448,3 & 465,0 & 429,4 \\
\hline $26 / 10-01 / 11$ & 571,3 & 570,6 & 566,5 & 564,6 & 556,4 & 553,7 & 541,6 & 539,1 & 523,2 & 521,6 & 502,3 \\
\hline $02-08 / 11$ & 551,2 & 546,9 & 550,0 & 537,7 & 543,5 & 524,1 & 532,4 & 507,0 & 517,5 & 487,6 & 500,0 \\
\hline $09-15 / 11$ & 673,4 & 665,0 & 675,6 & 560,6 & 671,2 & 631,2 & 661,0 & 607,9 & 645,9 & 582,0 & 627,2 \\
\hline $16-22 / 11$ & 596,0 & 586,4 & 601,6 & 571,7 & 601,3 & 552,8 & 595,6 & 530,4 & 585,4 & 506,1 & 571,7 \\
\hline $23-29 / 11$ & 556,0 & 544,1 & 562,9 & 527,6 & 564,2 & 507,3 & 560,4 & 484,2 & 552,2 & 459,6 & 540,6 \\
\hline $30 / 11-06 / 12$ & 581,8 & 568,9 & 589,1 & 551,1 & 590,6 & 529,3 & 586,6 & 507,7 & 578,1 & 478,4 & 566,1 \\
\hline $07-13 / 12$ & 511,6 & 498,8 & 521,2 & 481,6 & 525,6 & 461,0 & 525,0 & 438,2 & 520,2 & 413,9 & 512,0 \\
\hline $14-20 / 12$ & 479,7 & 466,7 & 488,3 & 449,9 & 492,0 & 429,8 & 491,1 & 407,7 & 486,2 & 384,4 & 478,2 \\
\hline
\end{tabular}

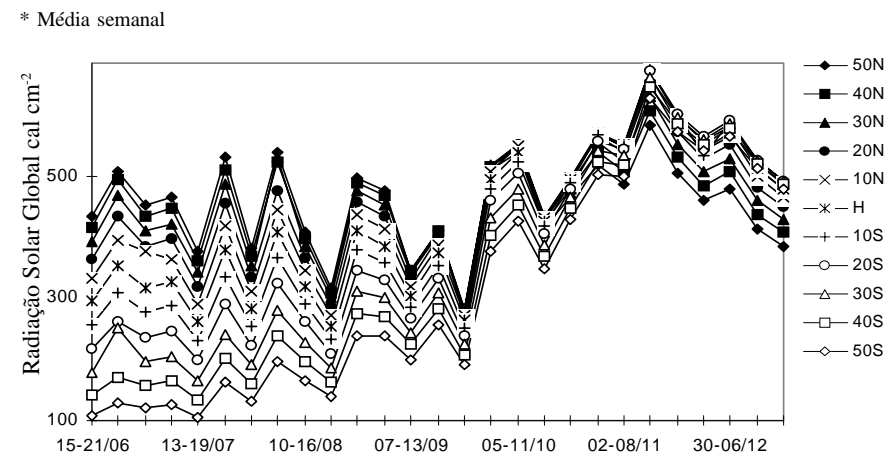

Figura 1. Radiação solar global e média semanal, em rampas com $0,10,20,30,40$ e $50 \%$ de declividade e exposições norte e sul

Os valores obtidos nesta pesquisa estão em concordância com aqueles obtidos por Lopes (1973), Latanze (1973) e Benincasa (1976) que desenvolveram trabalhos em condições semelhantes.

\section{Temperatura e umidade do solo}

A radiação solar que incidiu sobre a superfície do substrato influenciou, sobremaneira, a temperatura e a umidade do meio, como pode ser observado pelas Tabelas 3 e 4, respectivamente.

Os valores de temperatura obtidos durante a pesquisa demonstram haver correlação direta desta com a radiação solar incidente (Figura 2). Ao se comparar as Figuras 1 e 2, percebese claramente que ambas possuem a mesma configuração, comprovando que as variações de radiação solar incidente correspondem às variações equivalentes da temperatura do substrato.

Pode-se afirmar, portanto, que a medida da temperatura é um excelente indicador microclimatológico do efeito da radiação solar sobre uma superfície vegetada ou não, estando em concordância com este fato vários autores, entre eles van Wijk (1965), Benincasa (1972) e Lopes (1973). 
Tabela 3. Temperatura do solo*, às 13:00 horas, a $2 \mathrm{~cm}$ de profundidade, nas declividades de 0, 10, 20, 30, 40 e 50\% e exposições norte e sul

\begin{tabular}{|c|c|c|c|c|c|c|c|c|c|c|c|}
\hline \multirow[t]{2}{*}{ Períodos } & \multicolumn{11}{|c|}{ Temperatura $\left({ }^{\circ} \mathrm{C}\right)$} \\
\hline & $\mathrm{H}$ & $10 \mathrm{~N}$ & $10 \mathrm{~S}$ & $20 \mathrm{~N}$ & $20 \mathrm{~S}$ & $30 N$ & $30 \mathrm{~S}$ & $40 N$ & $40 \mathrm{~S}$ & $50 \mathrm{~N}$ & $50 \mathrm{~S}$ \\
\hline $15-21 / 06$ & 28,7 & 30,3 & 27,2 & 29,5 & 25,3 & 29,4 & 25,4 & 30,9 & 23,6 & 30,4 & 21,9 \\
\hline $22-28 / 06$ & 32,1 & 33,9 & 30,0 & 34,1 & 28,7 & 34,2 & 27,3 & 36,9 & 24,6 & 35,6 & 22,5 \\
\hline $29 / 06-05 / 07$ & 34,0 & 35,8 & 32,4 & 35,3 & 31,9 & 35,5 & 30,3 & 38,5 & 28,3 & 36,1 & 26,3 \\
\hline $06-12 / 07$ & 32,9 & 34,6 & 31,5 & 34,7 & 30,2 & 35,0 & 28,8 & 37,5 & 27,1 & 36,0 & 25,1 \\
\hline $13-19 / 07$ & 25,5 & 26,3 & 25,3 & 26,5 & 24,7 & 26,5 & 24,3 & 27,6 & 23,0 & 26,9 & 22,3 \\
\hline $20-26 / 07$ & 35,9 & 36,8 & 34,4 & 37,9 & 33,5 & 38,5 & 32,6 & 41,3 & 28,8 & 39,2 & 28,2 \\
\hline $27 / 07-02 / 08$ & 33,5 & 34,4 & 32,6 & 34,7 & 32,0 & 35,0 & 30,9 & 37,0 & 29,0 & 36,1 & 28,2 \\
\hline $03-09 / 08$ & 37,8 & 37,9 & 37,9 & 39,3 & 35,9 & 40,4 & 34,8 & 41,8 & 33,1 & 43,1 & 31,4 \\
\hline $10-16 / 08$ & 33,2 & 33,8 & 33,5 & 34,7 & 31,5 & 34,6 & 30,3 & 36,3 & 29,3 & 37,5 & 27,6 \\
\hline $17-23 / 08$ & 27,4 & 27,5 & 26,9 & 27,9 & 26,1 & 27,6 & 25,5 & 28,4 & 24,3 & 28,4 & 23,5 \\
\hline $24-30 / 08$ & 28,6 & 28,6 & 28,2 & 29,0 & 27,5 & 28,9 & 26,8 & 29,5 & 25,6 & 29,3 & 25,2 \\
\hline $31 / 08-06 / 09$ & 35,4 & 35,4 & 34,9 & 36,1 & 34,2 & 35,7 & 32,9 & 36,8 & 31,9 & 35,4 & 30,6 \\
\hline 07-13/09 & 30,3 & 30,3 & 30,3 & 30,6 & 29,8 & 30,5 & 29,1 & 31,3 & 28,2 & 30,5 & 27,9 \\
\hline $14-20 / 09$ & 33,2 & 32,9 & 32,7 & 32,8 & 32,1 & 33,4 & 31,2 & 33,6 & 29,9 & 32,8 & 29,8 \\
\hline $21-27 / 09$ & 30,7 & 36,4 & 30,5 & 30,3 & 30,3 & 30,5 & 30,0 & 30,7 & 29,1 & 29,8 & 29,4 \\
\hline 28/09-04/10 & 35,2 & 34,9 & 34,4 & 34,9 & 33,9 & 34,9 & 33,7 & 35,7 & 32,4 & 34,3 & 32,7 \\
\hline $05-11 / 10$ & 37,6 & 37,3 & 36,8 & 37,3 & 35,8 & 37,6 & 33,3 & 37,2 & 34,3 & 37,4 & 34,3 \\
\hline $12-18 / 10$ & 42,4 & 41,8 & 41,9 & 41,6 & 40,6 & 41,5 & 42,2 & 40,6 & 39,4 & 40,5 & 39,5 \\
\hline $19-25 / 10$ & 41,6 & 41,5 & 40,9 & 41,1 & 40,1 & 41,0 & 40,4 & 41,0 & 38,4 & 40,5 & 37,9 \\
\hline $26 / 10-01 / 11$ & 36,4 & 36,1 & 36,0 & 36,1 & 35,4 & 35,6 & 35,1 & 35,4 & 33,9 & 35,6 & 33,9 \\
\hline $02-08 / 11$ & 47,7 & 47,2 & 47,5 & 46,4 & 46,4 & 46,1 & 45,1 & 45,2 & 44,1 & 47,0 & 37,3 \\
\hline $09-15 / 11$ & 40,3 & 40,3 & 39,9 & 40,6 & 38,9 & 39,5 & 39,5 & 39,6 & 38,7 & 38,9 & 38,5 \\
\hline $16-22 / 11$ & 44,1 & 44,3 & 43,9 & 42,2 & 42,4 & 42,7 & 43,9 & 42,5 & 42,9 & 42,6 & 43,1 \\
\hline $23-29 / 11$ & 36,0 & 35,3 & 36,0 & 35,8 & 35,4 & 34,7 & 36,1 & 34,5 & 35,0 & 33,8 & 35,5 \\
\hline $30 / 11-06 / 12$ & 48,0 & 47,7 & 47,9 & 46,3 & 47,4 & 45,9 & 47,3 & 45,0 & 46,4 & 46,0 & 46,1 \\
\hline $07-13 / 12$ & 43,6 & 43,3 & 43,8 & 42,9 & 43,8 & 41,9 & 43,9 & 41,1 & 43,3 & 41,5 & 43,4 \\
\hline $14-20 / 12$ & 42,2 & 41,2 & 41,1 & 40,7 & 41,9 & 40,3 & 42,3 & 39,3 & 41,3 & 39,2 & 40,9 \\
\hline
\end{tabular}

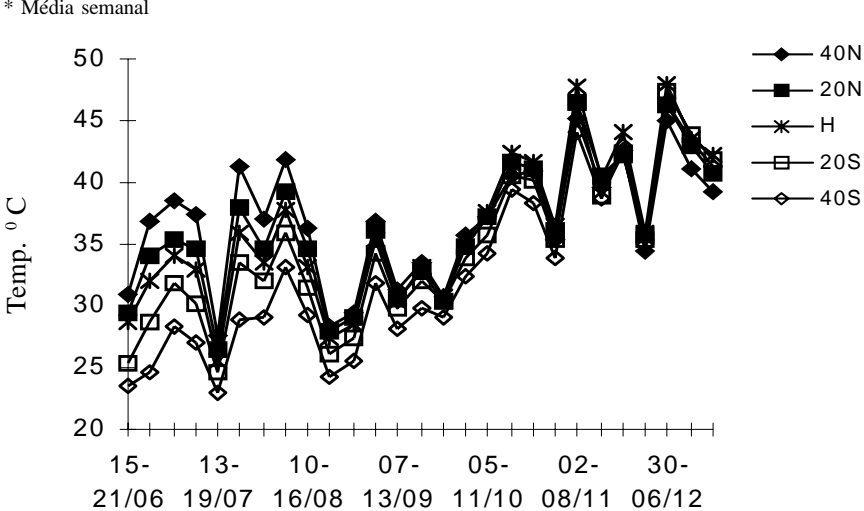

Figura 2. Temperatura do solo às 13:00 h, média semanal, à profundidade de $2 \mathrm{~cm}$, nas declividades de 0, 20 e $40 \%$, exposições norte e sul, ao longo do período experimental
Ao se analisar os dados de umidade percebe-se, também, a ação da radiação solar/temperatura; neste caso, aos maiores valores de radiação solar correspondem os menores de umidade (Tabelas 2 e 4).

A análise da Tabela 4 permite verificar, ainda, os baixos valores de umidade obtidos no início do período experimental (15/06 a 13/08) devido à alta incidência de radiação solar (Tabela 2) e alta temperatura (Tabela 3 ) além da escassez de chuvas no período.

A partir do dia 13/08 optou-se por irrigar as rampas, com o objetivo de se observar o comportamento dos demais parâmetros estudados. A irrigação das rampas foi paralisada no dia 02/09 quando, então, as chuvas se tornaram mais freqüentes.

Diferenças marcantes entre as declividades e as exposições, devido ao efeito da radiação solar, são mais evidentes no período 
Tabela 4 Umidade diária do solo* em rampas com declividades de 0, 10, 20, 30, 40 e 50\% e exposições norte e sul

\begin{tabular}{|c|c|c|c|c|c|c|c|c|c|c|c|}
\hline \multirow[t]{2}{*}{ Dias/Mês } & \multicolumn{11}{|c|}{ Umidade $\left(\mathrm{g} \mathrm{kg}^{-1}\right)$} \\
\hline & $\mathrm{H}$ & $10 \mathrm{~N}$ & $10 \mathrm{~S}$ & $20 \mathrm{~N}$ & $20 \mathrm{~S}$ & $30 \mathrm{~N}$ & $30 \mathrm{~S}$ & $40 \mathrm{~N}$ & $40 \mathrm{~S}$ & $50 \mathrm{~N}$ & $50 \mathrm{~S}$ \\
\hline 08/06 & 215 & 215 & 215 & 215 & 215 & 215 & 215 & 215 & 215 & 215 & 215 \\
\hline $15 / 06$ & 76 & 52 & 64 & 71 & 79 & 50 & 71 & 64 & 88 & 54 & 62 \\
\hline $22 / 06$ & 110 & 92 & 121 & 90 & 129 & 91 & 128 & 85 & 142 & 79 & 156 \\
\hline $29 / 06$ & 82 & 70 & 96 & 71 & 85 & 65 & 95 & 45 & 114 & 47 & 126 \\
\hline 06/07 & 85 & 56 & 92 & 53 & 100 & 39 & 87 & 45 & 95 & 48 & 95 \\
\hline $13 / 07$ & 88 & 73 & 93 & 61 & 104 & 86 & 96 & 65 & 97 & 57 & 118 \\
\hline $20 / 07$ & 61 & 41 & 68 & 38 & 43 & 47 & 26 & 64 & 69 & 91 & 88 \\
\hline $27 / 07$ & 67 & 48 & 77 & 35 & 78 & 39 & 69 & 44 & 93 & 39 & 97 \\
\hline $10 / 08$ & 50 & 37 & 54 & 35 & 67 & 26 & 71 & 35 & 71 & 31 & 92 \\
\hline $13 / 08$ & 224 & 228 & 234 & 231 & 236 & 235 & 230 & 226 & 233 & 228 & 223 \\
\hline $14 / 08$ & 222 & 222 & 233 & 224 & 243 & 239 & 223 & 229 & 209 & 233 & 208 \\
\hline $16 / 08$ & 249 & 253 & 257 & 254 & 253 & 252 & 248 & 251 & 256 & 242 & 243 \\
\hline $17 / 08$ & 146 & 144 & 160 & 151 & 159 & 141 & 162 & 147 & 171 & 139 & 169 \\
\hline $20 / 08$ & 246 & 247 & 245 & 254 & 246 & 250 & 245 & 242 & 247 & 243 & 240 \\
\hline $24 / 08$ & 225 & 224 & 224 & 232 & 228 & 230 & 232 & 229 & 229 & 224 & 227 \\
\hline $26 / 08$ & 144 & 137 & 143 & 128 & 152 & 133 & 142 & 126 & 156 & 128 & 148 \\
\hline $31 / 08$ & 229 & 211 & 224 & 216 & 226 & 206 & 223 & 206 & 228 & 207 & 226 \\
\hline 09/09 & 242 & 244 & 241 & 235 & 238 & 230 & 233 & 218 & 224 & 228 & 228 \\
\hline $14 / 09$ & 114 & 111 & 106 & 95 & 121 & 108 & 114 & 97 & 120 & 92 & 122 \\
\hline $21 / 09$ & 103 & 95 & 105 & 99 & 108 & 107 & 110 & 98 & 113 & 96 & 115 \\
\hline $28 / 09$ & 245 & 237 & 246 & 233 & 246 & 241 & 238 & 231 & 241 & 234 & 236 \\
\hline $05 / 10$ & 274 & 266 & 273 & 275 & 277 & 265 & 264 & 265 & 278 & 256 & 275 \\
\hline $19 / 10$ & 85 & 83 & 87 & 82 & 91 & 82 & 81 & 77 & 91 & 69 & 92 \\
\hline $26 / 10$ & 206 & 204 & 201 & 199 & 197 & 201 & 191 & 196 & 197 & 194 & 200 \\
\hline $09 / 11$ & 149 & 151 & 153 & 150 & 147 & 147 & 146 & 149 & 144 & 152 & 147 \\
\hline $16 / 11$ & 76 & 74 & 85 & 75 & 91 & 87 & 79 & 81 & 73 & 79 & 78 \\
\hline $23 / 11$ & 248 & 246 & 250 & 244 & 244 & 246 & 237 & 249 & 244 & 246 & 240 \\
\hline $30 / 11$ & 95 & 93 & 98 & 100 & 101 & 105 & 106 & 96 & 91 & 100 & 97 \\
\hline $07 / 12$ & 94 & 89 & 89 & 94 & 94 & 94 & 91 & 88 & 87 & 88 & 87 \\
\hline $14 / 12$ & 91 & 94 & 85 & 96 & 83 & 106 & 85 & 116 & 85 & 102 & 90 \\
\hline $21 / 12$ & 182 & 179 & 179 & 183 & 178 & 177 & 173 & 172 & 173 & 175 & 177 \\
\hline
\end{tabular}

inicial, anterior à irrigação, quando se verificou, que as rampas que receberam menor incidência dos raios solares, face sul, apresentaram maiores teores de umidade; em contrapartida, nas rampas norte, com maior quantidade de radiação solar, os teores de umidade foram muito baixos. Verificou-se, ainda, que a rampa horizontal $(0 \%)$ apresentou valores intermediários entre as declividades norte e sul.

A estreita relação entre a radiação solar e a umidade também é evidenciada por vários outros autores, dentre eles Klar (1984), Benincasa (1991) e Pavani (1993) que afirmam ser a radiação solar e a temperatura dois dos principais fatores a influenciar a perda de água no solo.

\section{Perdas de nitrato do solo}

Na Tabela 5 são apresentados os valores de nitrato obtidos para todas as rampas.

A análise dos dados permite distinguir dois períodos durante o experimento, antes e após a fase de irrigação.

Nas condições iniciais, entre 22/06 e 12/08, o substrato foi submetido a condições de umidade muito baixas devido à ausência de precipitação.

Segundo Gadet et al. (1961) apud Primavesi (1985) os nitratos não são bem adsorvidos por solos secos, por subirem totalmente à superfície seca e insolarada, de onde a raiz não o pode retirar por falta de água e excesso de calor; então, pode-se

Tabela 5. Teor de nitrato no solo* em rampas com $0,10,20,30,40$ e 50\% de declivide e exposições norte e sul

\begin{tabular}{rrrrrrrrrrrr}
\hline Dias & \multicolumn{10}{c}{ Nitrato $\left(\mathrm{mg} \mathrm{dm}^{-3}\right)$} \\
\cline { 2 - 12 } & \multicolumn{1}{c}{ H } & $10 \mathrm{~N}$ & $10 \mathrm{~S}$ & $20 \mathrm{~N}$ & $20 \mathrm{~S}$ & $30 \mathrm{~N}$ & $30 \mathrm{~S}$ & $40 \mathrm{~N}$ & $40 \mathrm{~S}$ & $50 \mathrm{~N}$ & $50 \mathrm{~S}$ \\
\hline $22 / 06$ & 65 & 108 & 117 & 100 & 77 & 97 & 78 & 104 & 85 & 102 & 53 \\
$17 / 08$ & 11 & 8 & 8 & 6 & 7 & 6 & 6 & 9 & 6 & 7 & 5 \\
$21 / 09$ & 9 & 14 & 12 & 9 & 8 & 13 & 11 & 17 & 8 & 16 & 12 \\
$09 / 11$ & 11 & 12 & 15 & 10 & 18 & 12 & 19 & 14 & 12 & 18 & 12 \\
$21 / 12$ & 16 & 9 & 7 & 7 & 8 & 9 & 9 & 8 & 11 & 6 & 7 \\
\hline
\end{tabular}


explicar os valores obtidos na primeira amostragem, uma vez que as amostras do substrato foram coletadas da camada superficial $(0-5 \mathrm{~cm})$ em condições de baixa umidade.

Observou-se, a partir dos valores apresentados na amostragem do dia 17/08 ( $2^{\mathrm{a}}$ amostragem) caracterizada por período antecedente com umidade elevada devido ao início da irrigação, queda acentuada do conteúdo de nitrato do solo em todas as rampas, independente da declividade ou exposição, em relação à amostragem do dia 22/06 ( $1^{\text {a }}$ amostragem) caracterizada por período seco antecedente. Para facilitar a visualização deste fato, elaborou-se a Tabela 6 , na qual se apresentam valores que reproduzem a porcentagem de perda de nitrato entre a primeira (antes da irrigação) e a segunda avaliação (após a irrigação). Analisando-se os valores apresentados verifica-se que a rampa horizontal $(0 \%)$ conservou maior quantidade de nitrato, embora não se possa definir uma sequiência, entre as demais rampas, que correlacione os valores obtidos com a declividade ou com a exposição.

Após a paralisação da irrigação (02/09) devido à ocorrência de chuvas mais freqüentes, o teor de nitrato sofreu um leve acréscimo em quase todas as rampas (21/09 e 09/11); em seguida, na amostragem do dia 21/12, acredita-se já haver ocorrido uma adaptação da microvida do substrato às novas condições ambientais. Nessa época, as rampas com face sul já recebiam maior quantidade de radiação solar, embora a diferença entre as exposições ainda fosse pequena (Tabela 2). A intensidade da radiação solar também sofreu aumento generalizado em todas as rampas, o que refletiu na temperatura do substrato (Tabela 3 ) e na umidade, a qual oscilou entre valores altos e baixos, por influência das precipitações (Tabela 4).

Ao se avaliar as perdas totais de nitrato durante o período experimental, observa-se haver tendência das rampas norte apresentarem as maiores perdas e a rampa horizontal, a menor. A Figura 3 mostra as porcentagens de perda de nitrato entre a primeira (22/06) e a última amostragem (21/12) em todas as rampas. Esses resultados permitem inferir que a incidência diferenciada da radiação solar sobre o substrato provocou mudanças na sua temperatura e umidade e que esses parâmetros influenciaram nas perdas de nitrato ao longo do período experimental. Apesar da acentuada perda de nitrato por lixiviação no período em que se efetuou a irrigação, os valores finais demonstram claramente a tendência acima mencionada, permitindo inferir que condições de alta temperatura aliada à elevada umidade, causada pela irrigação ou precipitação, favoreceram as perdas de nitrato nas rampas com exposição norte. A definição de locais com estas características pode ter facilitado a atividade das bactérias desnitrificadoras, que promoveram perdas de nitrato em condições de alta temperatura e deficiência de oxigênio (irrigação ou precipitação). Em trabalho realizado por Sexstone et al. (1985) foram avaliadas perdas de nitrato por desnitrificação devido à irrigação e precipitação. Os autores observaram haver um período que reflete o tempo necessário para estabelecer condições de desnitrificação quando do molhamento do solo. Este período, concluem os autores, é mais limitante que as restrições físicas causadas pela falta de

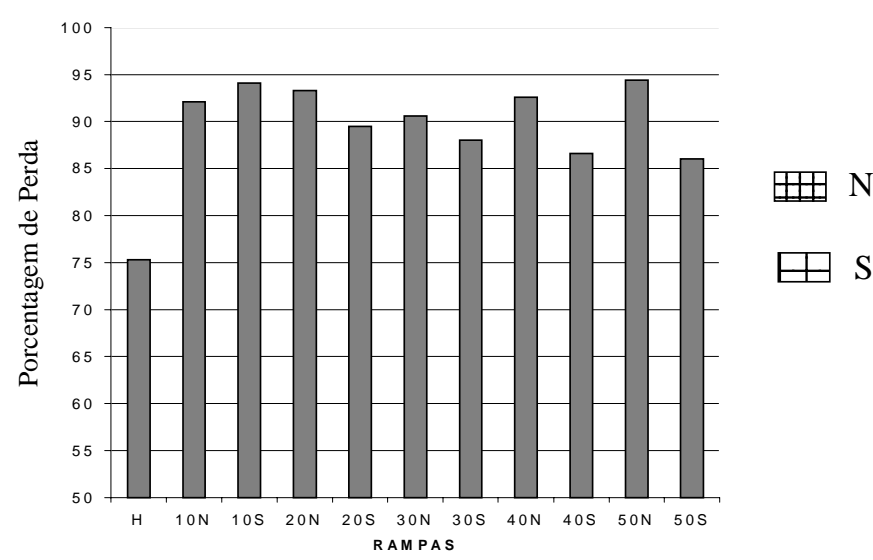

Figura 3. Porcentagem de perda de nitrato durante o período experimental em rampas com diferentes declinidade

difusão do gás. Este comentário pode explicar os valores obtidos entre a segunda e a última avaliação, acreditandose que se tenha estabelecido uma comunidade microbiana capaz de promover a desnitrificação. A utilização do efluente de biodigestor anaeróbio como fonte de matéria orgânica e nutrientes é outro fato relevante a ser considerado. Segundo Kiehl (1985) a matéria orgânica do solo constitui um reservatório de nitrogênio que nunca está completamente vazio e, outras vezes, suficientemente cheio para garantir a produção máxima da maioria das culturas. Assim, mesmo não havendo reposição de efluente no decorrer do experimento, devido à mineralização do material no período, pode ter havido formação de nitrato, como demonstram os valores das terceira e quarta avaliações nas quais se observam pequenos acréscimos, com posterior decréscimo. Ao se classificar as perdas totais de nitrato através da porcentagem, demonstradas na Figura 3, observou-se a seguinte seqüência crescente de valores: H $(75,3) ; \mathbf{5 0 S}(86,0)$; 40S $(86,6) ; 30 S(88,0) ;$ 20S $(89,5) ; 30 N(90,6) ; 10 N(92,1) ; 40 N$ $(92,6) ; \mathbf{2 0 N}(93,3) ; \mathbf{1 0 S}(94,1)$ e $\mathbf{5 0 N}(94,4)$. Nesta sequiência e apesar da classificação da rampa 10S, pode-se inferir que, quanto menor a quantidade de radiação solar recebida no período, maior a conservação de nitrato, pois este parâmetro, por influenciar na determinação de diferentes microclimas, alterou a dinâmica da matéria orgânica do solo e, por conseguinte, o ciclo do nitrogênio.

\section{CONCLUSÕES}

1. A intensidade da radiação solar definiu as condições microclimatológicas de cada rampa, sendo a temperatura diretamente proporcional à radiação solar, enquanto a umidade se relacionou inversamente.

2. As perdas de nitrato no solo foram mais acentuadas durante o período de irrigação, evidenciando o efeito da lixiviação.

3. A avaliação final das perdas de nitrato evidenciou que as rampas com exposição norte apresentaram maior porcentagem de perda de nitrato que as rampas com exposição sul, sendo a rampa horizontal a que apresentou as menores perdas.

Tabela 6. Porcentagem de perda de nitrato entre a $1^{\mathrm{a}}$ e a $2^{\mathrm{a}}$ avaliação

\begin{tabular}{lccccccccccc}
\hline Rampas & $\mathrm{H}$ & $10 \mathrm{~N}$ & $10 \mathrm{~S}$ & $20 \mathrm{~N}$ & $20 \mathrm{~S}$ & $30 \mathrm{~N}$ & $30 \mathrm{~S}$ & $40 \mathrm{~N}$ & $40 \mathrm{~S}$ & $50 \mathrm{~N}$ & $50 \mathrm{~S}$ \\
\hline \% Perda & 83,5 & 92,3 & 92,9 & 93,8 & 90,6 & 93,9 & 92,4 & 91,7 & 92,4 & 93,0 & 89,9 \\
\hline
\end{tabular}




\section{REFERÊNCIAS BIBLIOGRÁFICAS}

AGIODA, A.; MERLO, C.; CARMANTRAND, J.C.S.; JAMER, P. Efeitos da agricultura sobre o abastecimento de água: exemplos franceses e italianos. In: CONFERÊNCIA SOBRE AGRICULTURA E MEIO AMBIENTE, 1992, Viçosa. Anais...Viçosa: UFV/NEPEMA, 1994. p.1-24.

BENINCASA, M. Contribuição ao estudo ecológico do feijoeiro comum (Phaseolus vulgaris $L$.): efeitos térmicos no solo. Jaboticabal: Faculdade de Ciências Agrárias e Veterinárias, UNESP. 1972. 113p. Tese Doutorado

BENINCASA, M. Efeitos de rampas com diferentes declividades e exposições Norte e Sul de uma bacia hidrográfica sobre o microclima e produtividade biológica do Sorghum bicolor (L) Moench. Jaboticabal: Faculdade de Ciências Agrárias e Veterinárias, UNESP. 1976. 109p. Tese Livre Docência

BENINCASA, M. Algumas relações entre a bacia hidrográfica, o microclima e o comportamento vegetal. In: TAUK, S.M., GOBBI, N., FOWLER, H.G. (Org.). Análise Ambiental: uma visão multidisciplinar. São Paulo: UNESP-FAPESP, 1991. p.120-25.

EVANS, D.D.; WHITE, J.L.; ENSMINGER, L.E. and CLARK, F. E. Methods of soil analysis. Madison: American Society of Agronomy, 1965. p.1212-1219.

KIEHL, E.J. Fertilizantes orgânicos. Piracicaba: Agronômica Ceres, 1985. 492p.

KLAR, A.E. $A$ água no sistema solo-planta-atmosfera. São Paulo: Nobel, 1984. 408p.

LATANZE, R.J. Estudos ecológicos de feijoeiro (Phaseolus vulgaris $L$.) Efeitos das exposições norte e sul. Jaboticabal: Faculdade de Ciências Agrárias e Veterinárias, UNESP. 1973. 109p. Tese Doutorado
LATANZE, R.J.; BENINCASA, M.; LOPES, L.R. Bacia hidrográfica: estimativa da radiação solar incidente sobre superfícies com diferentes orientações. In: CONGRESSO BRASILEIRO DE ENGENHARIA AGRÍCOLA, 16, 1987, Jundiaí. Anais...Jundiaí, SBEA, 1987. p.17.

LOPES, L.R. Efeitos da exposição sobre o microclima da cultura do sorgo (Sorghum vulgaris Pers). Jaboticabal: Faculdade de Medicina Veterinária e Agronomia Prof. Antonio Ruete.1973. 105p. Tese Doutorado

ODUM, E.P. Ecologia. Rio de Janeiro: Guanabara, 1988. 434p.

PAVANI, L.C. Efeitos da orientação norte-sul e leste-oeste das linhas de plantas, das exposições norte e sul e da declividade da superfície sobre o balanço de radiação e o consumo de água da cultura de sorgo sacarino (Sorghum bicolor ( L. ) Moench). Botucatu: Faculdade de Ciências Agronômicas, UNESP. 1993. 174p. Tese Doutorado

PRIMAVESI, A. Manejo ecológico do solo: a agricultura em regiões tropicais. 8 ed. São Paulo: Nobel, 1985. 306p.

SIQUEIRA, J.O. e FRANCO, A.A. Biotecnologia do solo: fundamentos e perspectivas. Brasília: MEC/ABEAS, 1988. 236p.

SIQUEIRA, J.O.; MOREIRA, F.M.S.; GRISI, B.M.; HUNGRIA, M. e ARAÚJO, R.S. Microrganismos e processos biológicos do solo: perspectiva ambiental. Brasília: EMBRAPA-SPI, 1994. 142p.

SEXSTONE, A.J.; TIMOTHY, B.P. and TIEDJE, J.M. Temporal response of soil denitrification rates to rainfall and irrigation. Soil Sci. Soc. Am. J., Madison, v.49, p.99-103, 1985.

Van WIJK, W.R. Soil microclimate, its creation, observation and modification. In: AGRICULTURAL METEOROLOGY. v.6, p. 59-73, 1965. 